\title{
The Influence of Smart Tourism on Tourist Experience Toward Travel Intention and Satisfaction: Evidence from China
}

\author{
Chen $\mathrm{CHEN}^{1}$ \\ ${ }^{1}$ Assistant Professor; City University of Macau, Macau \\ Correspondence: Chen CHEN, Assistant Professor; City University of Macau, Macau. E-mail: cchen@cityu.mo
}

Received: July 2, $2020 \quad$ Accepted: August 6, $2020 \quad$ Online Published: August 19, 2020

doi:10.5539/ijms.v12n3p65 URL: https://doi.org/10.5539/ijms.v12n3p65

\begin{abstract}
This study is inspired by the rapid spread of smart tourism product/service involved in travel experiences, which has dramatically changed tourist behavioral and has stimulated tourist satisfaction with tourism destination. The aim of this study is to investigate the interrelationship among the tourist experience, tourist perceived value, tourist satisfaction and behavioral intention in regard to smart tourism products and services. Quantitative research method applies for the empirical tests. The results have significant emphasized the importance of smart tourism product/service in improving destination competitive.
\end{abstract}

Keywords: smart tourism product/service, tourist experience, perceived value, tourist satisfaction, behavioral intention

\section{Introduction}

The accelerating and synergistic interaction between information and communication technology (ICT) and tourism has brought fundamental change in tourism service and has greatly influenced consumer behavior. Bring 'smartness' into tourism can be seen as a logical progression and innovation for the tourism industry. Until 2013, China had 19 provinces proposing smart tourism development plans (Wang, Li, \& Li, 2013). Other countries have also positively improved their destination image or tourist experience by innovatively applying smart tourism technology. Currently, tourist experiences is undergoing a transformation as: (a) consumers now play a more active part in co-creating their own experiences; and (b) technology is increasingly mediating tourist experiences.

Studies on smart tourism have tended to focus narrowly on the adoption of ICT and general technology usage in regard to certain aspects of the tourism sector such as smart tourism destination(e.g., Buhalis \& Amaranggana, 2004; Rayman-Bacchus \& Molina, 2001), or on the impact of ICT on customer behavior (e.g., Tussyadiah \& Fesenmaier, 2009; Sweeney \& Soutar, 2001). It is posited in this paper that an understanding of smart tourism in the tourism sector lies not only in examining the adoption of technology in tourism, but also exploring how smart tourism has become embedded in the pre-trip, during-trip, and post-trip stages of tourism, to, in turn, help smart tourism destinations understand the technological needs of tourists.

The ubiquity of smart tourism product or service during the travel process changes the nature of tourists' demands and contributes to emerging uncertainty about what it is tourists' value. Therefore, this study aims at investigating value propositions in regard to the tourist experience in the context of smart tourism product/service. Taking a broader perspective, this study examines how smart tourism has become a vital element of the traveling process and explores how smart tourism destinations in China is linked to the tourist experience in a more holistic view.

\section{Theoretical Background and Conceptual Model}

\subsection{From Traditional Tourist Experience to "Smart” Tourism Experience}

Tourists seek benefits from the consumption of the experiential characteristics (i.e., physical, social and cultural) of places, spaces and landscapes (Tussyadiah \& Zach, 2012). Some scholars emphasize that tourism is associated with experiences that involve multi-sensory dimensions. In the area of marketing, Schmitt (1999) introduces experience into five dimensions: sensory experience (sensing), emotional experience (feeling), thinking experience (thought), operational experience (action), and related experiences (belonging). The advent of the new information and technology, such as mobile internet, cloud computer, Internet of Things etc., with its multiple functions inherent as a source of information, user generated content and platform for interaction has dramatically 
changing the tourist behavior and tourism industry (Buhalis \& Law, 2008). By integrating smart tourism, this paper considers smart tourism in entire travel stages, from pre-travel, destination on-site, to the post-travel phase to actively engaged tourists co-creating their travel experience and enhanced their experience from following dimensions.

\subsubsection{Physical, Sensory Experience}

New technological developments contribute to improve the quality of tourism product or service and enhance the tourist sensory experience. For example, virtual tours have become a way that allows an actual visual experience (Cho, 2000). Compelling and engaging digital experience that captures all of the human senses. Increasing amount of emerging technologies, gradually, devote to the development of sensory experience of tourist. In fact, sensations (the activation of sensory organs - eyes, ears, nose, skin, and taste receptors) play the role as the initiator of the individual's perception of the surrounding world, a process through which sensory inputs are selected, organized, and interpreted, resulting in a "conscious sensory experience" (Gretzel \& Xiang, 2015). Different from other products, considering the multi-phase nature of the tourist experience (before, during and after travel phase), the potential influence of information communication technologies (ICTs) at different periods during the trip may have various physical and virtual influence (Tussyadiah \& Fesenmaier, 2009). However, there is lack of empirical research with a holistic approach to the sensory human senses - sight, hearing, smell, taste, and touch — with respect to tourist experiences, particularly focusing on smart tourism, is evidenced by the literature.

\subsubsection{Education/Cognitive and Perceptual Experience}

The development of technology empowered the tourist who is becoming more knowledgeable and is seeking exceptional value for money and time (Buhalis \& Law, 2008). Prospective travelers have direct access to a much greater wealth of information provided by tourism organizations, private enterprises and increasingly by other users/consumers to learn more about destination and travel experience by various stages. From information search, to destination/product consumption and post experience engagement, ICTs offer a range of tools to facilitate and improve the process.

\subsubsection{Co-Creation and Engaged Experience}

In the era of information, tourists can easily receive sufficient knowledge or information to manage decision-making processes based on information or experience from other customers to co-create value (Pires \& Rita, 2006). With the technology development, customers are increasingly gaining power and control; meanwhile, the needs of customers have changing. Numerous tools that are available via mobile internet and internet to tourist design and creating their own travel plan, or share and discuss their travel experience with other. Scholars (Binkhorst \& Dekker, 2006; Prahalad \& Ramaswamy, 2003) indicated that co-creating experience, also named the "co-creation experience", which develops from the interaction of an individual at a specific time and place and the co-creation network contains all the people and things.

The above dimensions of tourist experience based on information and technology development which are identified from literature, and will be used as initial dimensions for tourism experience in scale development.

\subsection{The Role of Smart Tourism in Tourist Satisfaction}

To better understanding the specific satisfaction, some scholars identify the travel is a "linear" process. As one of the foundations for this line of research, divided recreational experience into five phases: "(1) an anticipation (2) a travel to the site segment (3) an on-site experience (4) a return travel component and (5) an extended recollection stage." They indicated that different satisfaction can be achieved through each of the phase, and determine the entire tourist satisfaction and experience. Within these phases, tourists utilize ICTs to complete a series of activities including information search, travel planning, making ticket, accommodation, destination etc. (Wang, Park, \& Fesenmaier, 2012).

To sum up, finding previous studies have forester research that has led to the notion of tourist satisfaction with the entire travel experience. Based on the above arguments, this study defines satisfaction with the entire travel experience, and explore how the smart tourism influence the tourist experience and satisfaction during three phases of travel.

\subsection{Perceived Value}

One of the most comprehensive perspective to define perceived value is as an experience outcome, and defining value as an interactive with preference experience (Holbrook, 1999). Sheth, Bruce and Barbara (1991) developed a multiple functional consumption value including social, emotional, functional, epistemic and conditional value, and they regard that these dimensions make varying contributions in different choice situations. As Sanchez, Luis, 
Rosa and Miguel (2006) further explained it, "such a multidimensional perspective captures the experiential view of value, which has conceptual support from the cognitive-affective-behavior paradigm". Based on above review, this study derives the dimensions from the theory of consumption value (Sheth et al., 1991) and technology adoption theory to identify constituent dimensions capturing the value experience of smart tourism destination (e-Value), including utilitarian value, emotional value, social value, perceived control and freedom, value for money, and user's cognitive effort.

\subsection{Theory Fundamental}

One of the central assumptions of this research is that value determines satisfaction which is found on expectancy-value theory (EVT), a paradigm widely used by consumer value theorists to explain a consumer's satisfaction with an object or behavior. Based on expectancy-value theories, this research chooses emotional value, social value and empowerment value as tourist satisfaction and behavior intention antecedent variables.

Adopted from prior scholars research findings, this study carefully considers developing appropriate interpretation the effect of smart tourism to tourism experiences in various travel stage (pre-, during-, after-) (1) anticipating and planning, 2) the tourism experience itself, and (3) post-trip reflection and reminiscing; with various characteristics smart tourism product/service. whereby consideration tourist experience should be categories as (1) physical experience (2) sensory experience (2) education experience (3) cognitive experience (4) co-create experience (5) engage experience at all stages of the visitor experience.

Finally, it should also be emphasized that much of the perceived value within the various stage's tourist activities within the context of perceived value, in which a firm connection between the tourist' instinct value and extinct value are considered. Based on the above literature discussed, the following conceptual framework and research assumptions are proposed. To reiterate, the study's research question is: "How tourist experience and perceived value within the context of smart tourism product/service affect tourist satisfaction and behavioral intention to the destination?"

\section{Research Methodology}

The study adapted the measurement items from previous studies and all scales include multiple items. Adopted from prior scholars' research findings, this study considered developing appropriate interpretation the effect of smart tourism to tourism experiences in various travel stage (pre-, during-, after-) with various characteristics smart tourism product/service.

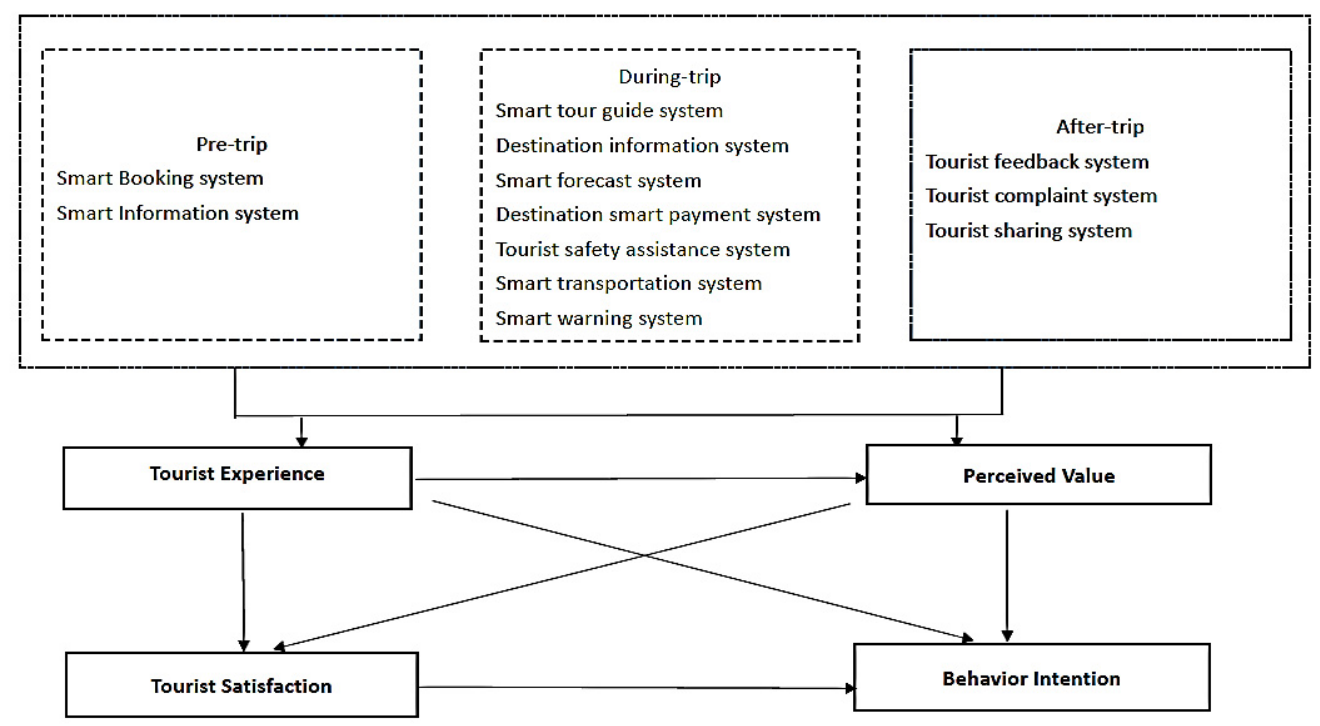

Figure 1. Conceptual model

This study derives the dimensions from the theory of consumption value (Sheth et al., 1991) and technology adoption theory capturing the value experience of smart tourism destination including utilitarian value, 
emotional value, social value, perceived control. Consequently, for the domain of interpretation the interrelationship with constructs, this study focuses on the tourist experience and interpretive perceived value as endogenous variable to access its effectiveness to exogenous variable tourist satisfaction and behavioral intention. After identifying the structure of the theoretical framework, the next step is to process the ways in which the exogenous variables might impact the endogenous variables in the model. More specifically, whether an effect from one construct on another in the model is positive or negative must be hypothesized before it can be incorporated into the data. The following research assumptions were made:

H1. Tourist experience has a direct effect on perceived value;

H2. Tourist experience has a direct effect on tourist satisfaction;

H3. Tourist experience has a direct effect on behavioral intention;

H4. Perceived value has a direct effect on tourist satisfaction;

H5. Perceived value has a direct effect on behavioral intention;

H6. Tourist satisfaction has a direct effect on behavioral intention.

The quantitative research including two stages. In the first stage, the preliminary questionnaire is used to collect data from a convenience sample. Pilot data in this stage improves the internal validity of the questionnaire. To further identify the dimensions of the scales, the SPSS applies to the analysis. All responses to the survey questionnaires enter into Statistical Package for Social Science (SPSS) for statistical analysis. Descriptive analysis is utilized to profile the characteristics of the respondents. Exploratory factor analysis (EFA) is applied to validate the constructs in the model. Construct validity and reliability are examined. SEM was adopted to assess the proposed hypothesized structural model.

This study adopted quota sampling based on the proportions of smart tourism destination geographic in China in terms of economic regions. The geographic coverage of the smart destinations attribute to sample into consideration. Because the statistics on each destination based on cities/provinces/areas is not feasible to conduct surveys. Therefore, it was appropriate to reference the destinations in four economic regions for sampling.

Table 1. KMO and Bartlett's test of sphericity

\begin{tabular}{lllll}
\hline Index & Name & Total Variance Explained & KMO & Bartlett's Test of Sphericity \\
\hline Tourist experience & L1-L14 & $62.63 \%$ & 0.879 & 0.0000 \\
Perceived value & L15-L24 & $64.80 \%$ & 0.889 & 0.0000 \\
Tourist satisfaction & L25-L27 & $77.14 \%$ & 0.714 & 0.0000 \\
Behavioral intentions & L28-L31 & $84.27 \%$ & 0.845 & 0.0000 \\
\hline
\end{tabular}

Table 2. Hypothesis testing result $(\mathrm{n}=500)$

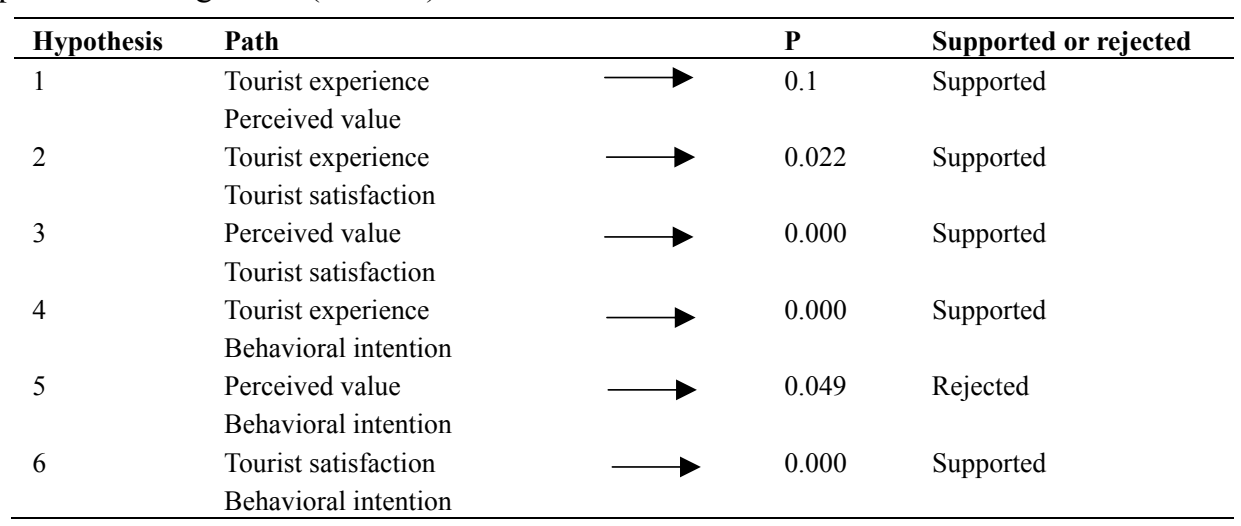

The SEM model examines by the sample survey data to obtain the best parameter estimates by maximizing the explained variance of the endogenous latent variables, which is widely used in the behavioral sciences. It can be viewed as a combination of factor analysis and regression or path analysis. The overall measurement model examined by all four constructs. The model fit indicated that the overall measurement model fit the data fairly well. The six hypotheses proposed based on the literature review were tested through Structure Equation Model. It indicated five of the six hypotheses were supported, while one rejected. 


\section{Discussion}

"Smart" has become a popular term to describe technological, economic and social development driven by smart technologies in China, especially, the revolution of the smartphone provides more opportunities to improve tourist experience. From the tourist viewpoint, tourist is not only a passive traveler, but to what extent tourists has become a producer as well as a partner and co-creators of a destination. With smart tourism product/service development, on-site consumption and activities has dramatically changed. According to this study, tourist experience and tourist perceived value greatly contribute to the tourist satisfaction, meanwhile, tourist satisfaction as the mediator influence the tourist behavioral intention. Stemming from the research finding, the destination and other tourist. Such tourist behavioral change may leads the destination's management perspective change. Traditional destination management may needs to shift from manager to facilitator to collaborate and participate in changing and learning environments to constantly integrated and collective with all stakeholder to increase the collaborative to improve the value-added service and knowledge-based service.

Based on the discussions in this study, there is an evidence to support that tourist experience and perceived value with smart tourism product/service has directly positive affect to the satisfaction with destination. The smart tourism development brings great innovation in fostering tourism destination development and marketing strategies. However, underlining the great investment of smart tourism, sustainable tourism in terms of technology. Tourism destination lay on sustainable in the economic, environmental, social, and cultural perspectives for long time.

Thirdly, further to the above recommendations, additional suggestions can be made based on this study's tourist experience and perceived value dimensions. (a) Utilitarian value is still the most significant value of most tourists concerns, but it cannot ignore the emotional value especially for the young generation who are grow up with technology development. (b) Fulfilling tourists' educational and cognitive needs, especially for the humanistic resources. (c) Ensuring the effectively delivery smart tourism content to tourist and potential tourist. Overall, smart tourism as a technology cannot change the core essence of tourism service spirit, but it provides new way to understand tourists and improve the tourist experience and destination management. It should be acknowledged that smart tourism is an opportunity for upgrading the tourism stakeholders' product and service, there is a challenge to future sustainable development.

\section{Conclusion}

This study adopted quantitative approach to historically provide experiential data and literature to emphasis the tourist experience has direct affect to perceived value, tourist satisfaction and behavioral intention in the context of smart tourism product/service. The context of smart tourism as a new research context, both the definition and theory are still on discussing in academic and industry. There were some research concerted efforts to examine the practical case studies. Thus, this study provides evidence to both academic and industry to understanding the needs of tourists and perception to smart tourism product/service.

There are two main limitation to this research. This study more emphasis the significant of characteristics of smart tourism. Therefore, there may miss some potential and norms which might influence the tourist experience, perceived value and tourist satisfaction with smart tourism product/service in China.

Secondly, in line with the goal of this study, the target smart tourism was the smart tourism product/service as a whole; thus, this study was focused on the general experience and value of the system. This study did not address different products and service, whereas this study demonstrated the strong perceived experiential value under examination. For the future study, the additional other values could result from other insights into smart tourism product/service research

\section{Reference}

Binkhorst, E., \& Dekker, T. D. (2009). Agenda for Co-Creation Tourism Experience Research. Journal of Hospitality Marketing \& Management, 18, 2-3. https://doi.org/10.1080/19368620802594193

Buhalis, D., \& Amaranggana, A. (2014). Smart Tourism Destination. Information and Communication Technologies in Tourism, 553-564. https://doi.org/10.1007/978-3-319-03973-2_40

Buhalis, D., \& Law, R. (2008). Progress in Information Technology and Tourism Management: 20 years on and 10 years after the Internet. Tourism Management, 29(4), 609-623. https://doi.org/10.1016/j.tourman.2008.01.005

Cho, Y. H. (2000)). A Conceptual Framework for Evaluating Effects of a Virtual Tour. Vienna: Springer. https://doi.org/10.1007/978-3-7091-6291-0_28 
Fuller, J., Muhlbacher, H., \& Gregor, K. M. (2009). Consumer Empowerment through Internet-Based Co-creation. Journal of Management Information Systems, 26(3), 71-102. https://doi.org/10.2753/MIS0742-1222260303

Gilmore, J., \& Pine, B. (2002). Differentiating Hospitality Operations via Experiences: Why Selling Service is not enough. The Cornell Hotel and Restaurant Administration, 87-96.

Gretzel, U., Sigala, M., Xiang, Z., \& Koo, C. (2015). Smart Tourism: Foundations and Developments. Electron Markets, 25, 179-188. https://doi.org/10.1007/s12525-015-0196-8

Gretzel, U., \& Xiang, Z. (2015). Special Issue on Smart Tourism: Convergence of Information Technologies, Experiences, and Theories. Electronic Markets, 25(3), 175-177. https://doi.org/10.1007/s12525-015-0194-x

Holbrook, M. (1999). Consumer Value: A Framework for Analysis and Research. London: Routledge.

Pine, B., \& Gilmore, J. (2002). Differentiating Hospitality Operations via Experiences: Why Selling Service is not enough. The Cornell Hotel and Restaurant Administration, 87-96.

Pires, G., Stanton, J., \& Rita, P. (2006). The Internet, Consumer Empowerment and Marketing Strategies. European Journal of Marketing, 40(9), 936-949. https://doi.org/10.1108/03090560610680943

Prahalad, C., \& Ramaswamy, V. (2004). Co-creation experiences: The Next Practice in Value Creation. Journal of Interactive Marketing, 18(3), 5-14. https://doi.org/10.1002/dir.20015

Rayman-Bacchus, L., \& Molina, A. (2001). Internet-based Tourism Services: Business Issues and Trends. Futures, 33(7), 589-605. https://doi.org/10.1016/S0016-3287(01)00003-9

Sanchez, J., Luis, C., Rosa, M., \& Miguel, A. (2006). Perceived Value of the Purchase of a Tourism Product. Tourism Management, 27(3), 394-409. https://doi.org/10.1016/j.tourman.2004.11.007

Schmitt, B. (2002). Experiential Marketing. Journal of Marketing Management, 15(1), 53-67. https://doi.org/10.1007/978-3-322-86757-5_1

Sheth, J., Bruce, I. N., \& Barbara, L. G. (1991). Consumption Values and Market Choice. Cincinnati, Ohio: South Western Publishing.

Sweeney, J., \& Soutar, G. N. (2001). Consumer Perceived Value: The Development of a Multiple Item Scale. Journal of Retailing, 77(2), 203-220. https://doi.org/10.1037/t56704-000

Tussyadiah, I., \& Fesenmaier, R. D. (2009). Mediating the Tourist Experiences Access to Places via Shared Videos. Annals of Tourism Research, 36(1), 24-40. https://doi.org/10.1016/j.annals.2008.10.001

Tussyadiah, I., \& Zach, F. J. (2012). The Role of GEO-Based Technology in Place Experiences. Annals of Tourism Research, 39(2), 780-800. https://doi.org/10.1016/j.annals.2011.10.003

Wang, D., Parks, S., \& Fesenmaier, D. R. (2012). The Role of Smart phone in Mediating the Touristic Experience. Journal of Travel Research, 51(4), 371-387. https://doi.org/10.1177/0047287511426341

Wang, D., Xiang, R. L., \& Yunpeng, L. (2013). China's "smart tourism destination" initiative: A taste of the service-dominant logic. Journal of Destination Marketing \& Management, 2(2), 59-61. https://doi.org/10.1016/j.jdmm.2013.05.004

Zhang, L. Y., Lin, Z., \& Liu, M. (2012). The Theory of Smart Tourism. Tourism Tribune, 27(5), 33-38.

\section{Copyrights}

Copyright for this article is retained by the author, with first publication rights granted to the journal.

This is an open-access article distributed under the terms and conditions of the Creative Commons Attribution license (http://creativecommons.org/licenses/by/4.0/). 